\title{
Cross-sectional study of population-specific streptococcal antibody titres in Uganda
}

\author{
Emmy Okello, ${ }^{1}$ Meghna Murali, ${ }^{2}$ Joselyn Rwebembera, ${ }^{1}$ Jenifer Atala, ${ }^{1}$ \\ Asha C Bowen, ${ }^{3,4}$ Nada Harik, ${ }^{2}$ Gloria Kaudha, ${ }^{1}$ Samalie Kitooleko, ${ }^{1}$ \\ Chris Longenecker ${ }^{5,6}$ Emma Ndagire, ${ }^{1}$ Isaac Otim Omara, ${ }^{1}$ Linda Mary Oyella, ${ }^{1}$ \\ Tom Parks, ${ }^{7}$ Jafesi Pulle, ${ }^{1}$ Craig Sable, ${ }^{2}$ Rachel Sarnacki, ${ }^{2}$ Elizabeth Stein, ${ }^{8}$ \\ Meghan Zimmerman, ${ }^{9}$ Nicholas de Klerk, ${ }^{3}$ Jonathan Carapetis, ${ }^{3}$ Andrea Beaton
}

For numbered affiliations see end of article.

\section{Correspondence to}

Dr Andrea Beaton, Cincinnati Children's Hospital Medical

Center, Cincinnati, OH 45229, USA; andrea.beaton@cchmc.org

Received 17 January 2020 Revised 9 April 2020 Accepted 30 May 2020 Published Online First 29 June 2020

\section{Linked}

- http://dx.doi.org/10.1136/ archdischild-2020-318970

\section{Check for updates}

(C) Author(s) (or their employer(s)) 2020. No commercial re-use. See rights and permissions. Published by BMJ.

To cite: Okello E, Murali M, Rwebembera J, et al.

Arch Dis Child

2020;105:825-829.

\section{ABSTRACT}

Objective Despite substantial variation of streptococcal antibody titres among global populations, there is no data on normal values in sub-Saharan Africa. The objective of this study was to establish normal values for antistreptolysin $\mathrm{O}$ (ASO) and antideoxyribonuclease B (ADB) antibodies in Uganda.

Design This was an observational cross-sectional study. Setting This study was conducted at Mulago National Referral Hospital, which is located in the capital city, Kampala, and includes the Uganda Heart Institute.

Patients Participants (aged $0-50$ years) were recruited. Of 428 participants, 22 were excluded from analysis, and $183(44.4 \%)$ of the remaining were children aged 5-15 years.

Main outcome measures ASO was measured in-country by nephelometric technique. ADB samples were sent to Australia (PathWest) for analysis by enzyme inhibition assay: 80\% upper limit values were established.

Results The median ASO titre in this age group was $220 \mathrm{IU} / \mathrm{mL}$, with the 80th percentile value of $389 \mathrm{IU} / \mathrm{mL}$. The median ADB titre in this age group was $375 \mathrm{IU} / \mathrm{mL}$, with the 80th percentile value of $568 \mathrm{IU} / \mathrm{mL}$.

Conclusions The estimated Ugandan paediatric population standardised 80\% upper-limit-of-normal ASO and ADB titres is higher than many global populations. Appropriateness of using population-specific antibody cutoffs is yet to be determined and has important implications for the sensitivity and specificity of rheumatic fever diagnosis.

\section{INTRODUCTION}

Undiagnosed rheumatic fever (RF) results in a missed opportunity to offer prophylaxis against recurrent group A streptococcal (GAS) infections, the driver of RF and later rheumatic heart disease (RHD). ${ }^{1}$ The diagnosis of RF requires evidence of preceding GAS infection. ${ }^{2}$ This evidence can take the form of a positive rapid antigen test or microbiological culture, but more commonly requires serum streptococcal antibody testing to detect evidence of GAS infection prior to RF development. ${ }^{2}$ The two most common commercially available streptococcal antibody assays are antistreptolysin $\mathrm{O}$ (ASO) titre and anti-DNase B (ADB) titre, but a variety of interpretations exist regarding what constitutes elevated titres. $^{3}$

\section{What is already known on this topic?}

The diagnosis of rheumatic fever (RF) requires evidence of preceding streptococcal infection, most commonly elevated streptococcal antibody titres.

- The upper limit for these titres varies by population, but has not been explored in subSaharan Africa, where RF remains endemic.

\section{What this study adds?}

- This study provides population-specific values for streptococcal antibody titres in Uganda.

The 2015 Jones criteria, the most widely applied criteria for RF diagnosis, recommend assessing acute and convalescent ASO and ADB antibody titres, with a twofold increase over 2-4 weeks, ${ }^{4}$ as the most robust evidence of recent GAS infection. The 80th percentile cutoffs for ASO and ADB vary geographically, likely reflecting differences in background GAS exposure and potentially genetic variability in immune response. While investigations of population-based normal values have been conducted in North America, ${ }^{5}$ Asia, ${ }^{6-8}$ the Middle East $^{39}$ and the Pacific, ${ }^{10}$ there is limited data for upper limit of normal (ULN) values in Africa, and no data from East Africa.

The objective of the current study was to determine the ULN for ASO and ADB for children and adults in Uganda, using a parametric regression modelling technique, as previously described. ${ }^{11}$

\section{PATIENTS AND METHODS}

Study design

This was an observational cross-sectional study to establish the normal values for ASO and ADB antibodies in Uganda.

\section{Setting}

Uganda is a low-income country in East Africa home to approximately 44 million people and ranked 162 of 189 nations on the United Nations Development Program's 2017 Human Development Index. ${ }^{12}$ Approximately $84 \%$ of the population lives in 
rural areas, and $48 \%$ of the population is aged $<15$ years. This study was conducted at Mulago National Referral Hospital, which is located in the capital city, Kampala, and includes the Uganda Heart Institute, which provides tertiary cardiac services, including cardiac surgery and interventional cardiac catheterisation, for the country. Participants were recruited in April and May 2018.

\section{Determining ULN values for ASO and ADB}

Recruitment was achieved through advertisement at several primary schools in Kampala and by direct invitation of children ( $>1$ year) and adults ( $\leq 50$ years) accompanying siblings/parents to the Uganda Heart Institute. Recruitment targeted 400 participants: 100 participants in the two age strata known to have the highest background antistreptococcal antibody titres (5-10 years and $10-15$ years) and 50 participants from all other age strata (1-4 years, 15-24 years, 25-34 years, 35-50 years). Participants were prospectively screened for current or recent GAS infection. We excluded any participant who reported a history of RF, RHD or invasive GAS disease or history of sore throat or skin sores in the past 14 days. We also excluded participants who had a temperature of $>38.0^{\circ} \mathrm{C}$ on the day of enrolment. All participants underwent focused echocardiography by a cardiologist, with review of the left-sided cardiac valves. Those showing evidence of RHD according to the 2012 WHF criteria ${ }^{13}$ were also excluded.

\section{Sample collection, transport and testing}

Blood specimens were obtained by standard venipuncture and placed immediately in a cool box, a cooler with ice. Samples were transported to the laboratory on the day of collection. On arrival at the laboratory, the samples were centrifuged and the serum was divided into two aliquots. One aliquot was used to determine the ASO titre at MBN Laboratories in Uganda and the second aliquot was stored at $-80^{\circ} \mathrm{C}$. After all samples had been collected, the frozen aliquots were shipped on dry ice to Perth, Australia for ADB titre determination at PathWest Laboratories.

ASO titres were measured by nephelometric technique (Beckman Coulter, Fullerton, California, USA) as described previously. ${ }^{11}$ ADB titres were measured by enzyme inhibition assay (bioMérieux, Marcy l'Etoile, France), as described previously. ${ }^{11}$ Standardised controls provided by the manufacturer were used for calibration of both tests. Both methods provide an inexact figure for low titres (titres of $<60 \mathrm{IU} / \mathrm{mL}$ for ASO and titres of $<100 \mathrm{IU} / \mathrm{mL}$ for $\mathrm{ADB}$ ); for these values, we estimated mid-titre values (a titre of $30 \mathrm{IU} / \mathrm{mL}$ for ASO and a titre of $50 \mathrm{IU} /$ $\mathrm{mL}$ for ADB), as previously described. ${ }^{11}$

\section{Statistical methods}

We used an amended version of previously described techniques for constructing age-specific ASO and ADB titre reference ranges. ${ }^{11}$ We followed the procedures described by Wright and Royston ${ }^{14}$ using the Stata command xriml. The raw data for both ASO and ADB titres were transformed to normality and then fitted to regression curves using fractional polynomials to describe the non-linearity of the distributions with age. From the resulting fitted curves, we obtained median and 80\% upperlimit-of-normal values for five age groups and also by year of age for children aged 5-14 years. Data were analysed using Stata V.15.

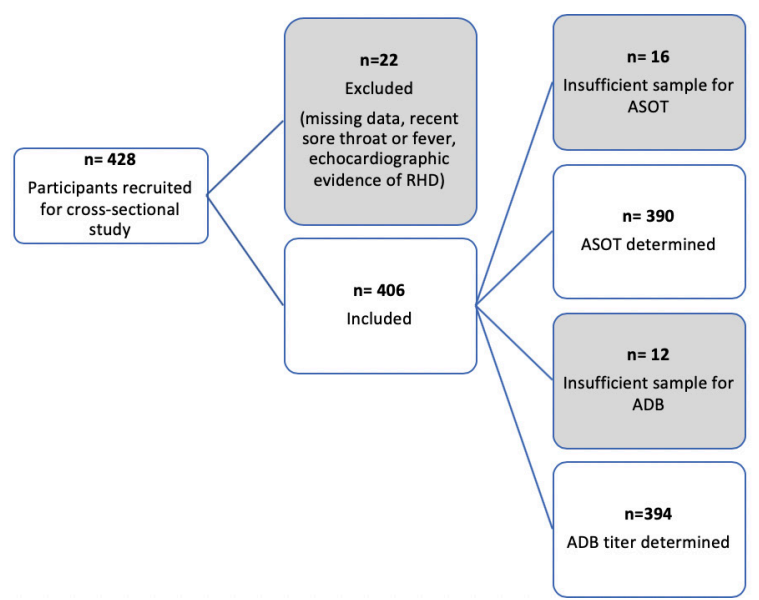

Figure 1 Participant flow chart. Grey cells indicate exclusions. ADB, antideoxyribonuclease $B ; A S O$, antistreptolysin $0 ;$ RHD, rheumatic heart disease.

\section{Ethical approval}

We approached all participants for their consent, and the study was explained by a research nurse in the participants' primary language. All participants provided written informed consent and assent was obtained from children aged 8 years or older.

\section{RESULTS}

In total, 428 participants were recruited of which $250(58 \%)$ were female. Of these 428 participants, 22 (5\%) were excluded: 6 for incomplete age data, 9 for sore throat in the last 14 days, 1 for skin sores in the last 14 days, 2 for fever on the day of enrolment and 4 for echocardiographic evidence of RHD. Additionally, 16 ASO titre samples and 12 ADB titre samples were not of sufficient quantity for processing, leaving 390 samples for ASO analysis and 394 samples for ADB analysis (figure 1).

When the data were log-transformed, there was one ADB value that was noted to be an extreme outlier $(2640 \mathrm{IU} / \mathrm{mL})$ and this value was removed. There were no extreme outliers for ASO and all values were retained for analysis.

There was a peak in the mean titres of both ASO and ADB in the age group 5-14 years, with a gradual decrease occurring following this peak (figure $2 \mathrm{~A}, \mathrm{~B}$ ). The estimated median and $80 \%$ upper-limit-of-normal values for five age groups are presented in table 1 . Table 2 presents these data in more detail for children aged 5-14 years. The estimated Ugandan paediatric population standardised $80 \%$ upper-limit-of-normal ASO and ADB titres were 389 and $568 \mathrm{IU} / \mathrm{mL}$, respectively.

\section{DISCUSSION}

GAS serological values, as seen in our study, consistently vary by age, with peak values in children aged 5-14 years. ${ }^{10} 111516$ Serological values have also been noted to vary by time of year in places with varied seasonal temperatures. ${ }^{3}{ }^{10}$ Both of these factors reflect differences in streptococcal exposure, not inherent differences in immunological response between populations. Differences in serological values attributable to GAS exposure is further confirmed by high ADB titres in Fiji reflecting high rates of GAS skin infection (more likely to cause an ADB response) compared with GAS sore throat, and possibly both the longer duration of $\mathrm{ADB}$ as compared with ASO response and the potential for cumulative serological responses where multiple infections are likely in the same person over a short time. ${ }^{11}$ 

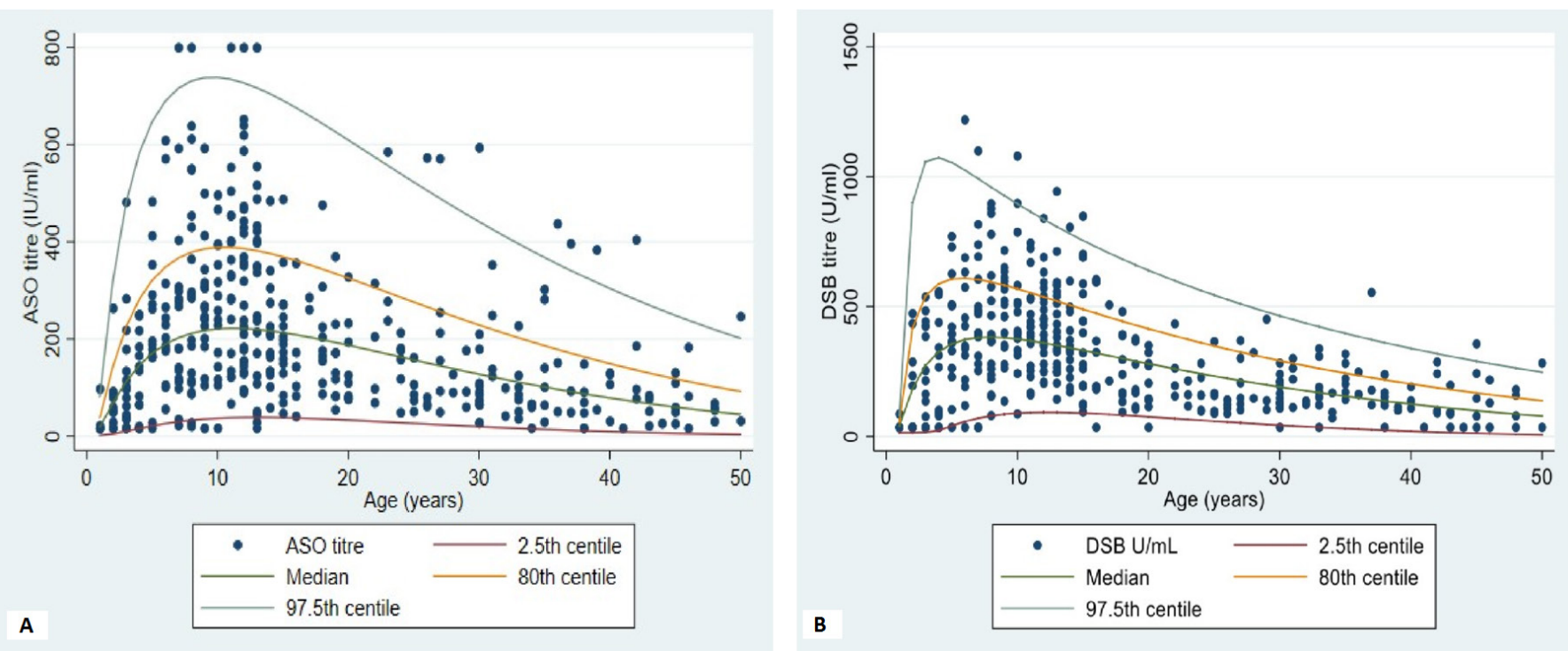

Figure 2 Antistreptolysin 0 (ASO) titre vs age (A) and antideoxyribonuclease B (ADB) titre vs age (B).

We found the normal values for streptococcal serology in Uganda to be higher than those reported in many other countries (table 3A, table 3B), although lower than New Zealand. ${ }^{17}$ This is aligned with other data from Uganda that streptotococcal burden in childhood is high. For example, 16\% of Ugandan children are colonised with GAS ${ }^{14}$ and GAS pharyngitis is common with an incidence of 10.3 cases per 100 child weeks. ${ }^{18}$ Approximately $2.5 \%$ of Ugandan school-going children show evidence of RHD by echocardiographic screening. ${ }^{19-21}$ Clinical RHD is diagnosed late, with $85 \%$ of patients diagnosed only at the time of advanced cardiac disease and complications. ${ }^{22}$ The average age of death from RHD in Uganda is 29 years. ${ }^{23}$ As our participants were recruited from a single urban centre, it is also possible that these values are not nationally representative.

Given that ASO and ADB titres can remain elevated for many months after GAS infection, ${ }^{24} 25$ there are some unknown number of people with recent GAS infection that were included, despite our attempt to screen with 14-day history. Recent pilot data from Northern Uganda found a very high number of children with GAS pharyngitis; $41 \%$ experienced a GAS-positive sore throat over 4 weeks of active surveillance. ${ }^{18}$ With this number of children experiencing GAS sore throat, population titres for unexposed children may be difficult to determine. The significance of this possibility in an RHD endemic area deserves further study. While historical data show $80 \%-90 \%$ of patients with RF will have streptococcal titres greater than the 80 th percentile cutoff, ${ }^{4}$ antibiody response may differ with more chronic GAS exposure and future work will address this question.

Table 1 Median and 80\% ULN reference values for ASO and ADB titres in Uganda by age group

\begin{tabular}{crrllllll}
\hline & \multicolumn{3}{c}{ ASO titre (IU/mL) } & & \multicolumn{3}{c}{ ADB titre (IU/mL) } \\
\cline { 2 - 4 } \cline { 7 - 8 } Age (year) & N & Median & $80 \%$ ULN & & N & Median & $\mathbf{8 0 \%}$ ULN \\
\hline $1-4$ & 46 & 92 & 185 & & 49 & 230 & 448 \\
\hline $5-14$ & 181 & 220 & 389 & & 183 & 375 & 568 \\
$15-24$ & 65 & 187 & 325 & & 65 & 280 & 415 \\
$25-34$ & 50 & 127 & 229 & & 49 & 191 & 292 \\
$35-50$ & 48 & 67 & 130 & & 48 & 109 & 181 \\
\hline
\end{tabular}

$A D B$, antideoxyribonuclease $B ; A S O$, antistreptolysin $0 ; U L N$, upper limit of normal.
Despite the limitations, these data provide the first contemporary values for normal streptococcal antibody titre ULN in East Africa. An ongoing community-based epidemiological study of RF in Uganda will explore the impact of using populationspecific rather than globally standardised ULN values for RF diagnosis in regard to sensitivity and specificity. Longitudinal follow-up of children with RF or possible RF will be particularly important for this work, to assess if use of higher cut-off values results in missed cases. Appropriate caution should be exercised in applying these values, given emerging data from New Zealand suggesting using higher population-specific titres may undercount RF cases. ${ }^{17}$

An additional concern is lack of diagnostic testing for GAS on the continent of Africa. Currently, there is no ABD testing available in Uganda, and the sensitivity and specificity of using the single ASO value will also be explored. New antibody panels, such as those containing SpnA, have shown early promise for expansion of testing platforms, but are not commercially available. ${ }^{26}$ Ideally, new platforms would be simple and affordable point-of-care tests in order to facilitate accurate RF diagnosis in the community as community-based RF diagnosis is one of the critical missing links to global RHD control.

Table 2 Median and $80 \%$ ULN reference values for ASO and ADB titres in Uganda by age (5-14 years)

\begin{tabular}{|c|c|c|c|c|c|c|}
\hline \multirow[b]{2}{*}{ Age (year) } & \multicolumn{3}{|c|}{ ASO titre $(\mathrm{IU} / \mathrm{mL})$} & \multicolumn{3}{|c|}{ ADB titre $(\mathrm{IU} / \mathrm{mL})$} \\
\hline & $N$ & Median & $80 \%$ ULN & $\mathrm{N}$ & Median & $80 \%$ ULN \\
\hline 5 & 14 & 170 & 321 & 14 & 357 & 606 \\
\hline 6 & 13 & 189 & 348 & 13 & 373 & 609 \\
\hline 7 & 18 & 202 & 367 & 19 & 381 & 604 \\
\hline 8 & 20 & 211 & 379 & 20 & 383 & 595 \\
\hline 9 & 18 & 217 & 386 & 17 & 380 & 582 \\
\hline 10 & 15 & 220 & 389 & 16 & 375 & 568 \\
\hline 11 & 18 & 222 & 389 & 18 & 368 & 553 \\
\hline 12 & 29 & 221 & 386 & 29 & 360 & 538 \\
\hline 13 & 21 & 219 & 382 & 21 & 351 & 522 \\
\hline 14 & 15 & 217 & 376 & 16 & 342 & 506 \\
\hline
\end{tabular}

$A D B$, antideoxyribonuclease $B ; A S O$, antistreptolysin 0 ; ULN, upper limit of normal. 
Table 3a ASO titre cut-off values for normal children (80\% ULN)

\begin{tabular}{|c|c|c|c|c|c|c|}
\hline Country & ULN & $\mathrm{N}$ & Age range & Technique & Year published & Handling of recent streptococcal infections \\
\hline India (Chandigarh) ${ }^{7}$ & $239 \mathrm{IU}$ & 200 & $5-15$ & $\begin{array}{l}\text { Microtitration haemolysin } \\
\text { inhibition }\end{array}$ & 2003 & $\begin{array}{l}\text { Medical record review, excluding previous history of recent throat infection. } \\
\text { No information provided on length of historical review. }\end{array}$ \\
\hline$U_{S A}^{5}$ & $240 \mathrm{IU}$ & 1131 & $2-12$ & $\begin{array}{l}\text { Microtitration haemolysin } \\
\text { inhibition }\end{array}$ & 1997 & $\begin{array}{l}1131 \text { children with acute pharyngitis with positive throat culture for GAS- } \\
\text { median time from symptoms to antibody titre } 1.77 \text { days, authors presume } \\
\text { levels reflect a healthy population, as titres peak later after infection. }\end{array}$ \\
\hline $\mathrm{Fiji}^{11}$ & $276 \mathrm{IU}$ & 186 & $5-14$ & Nephlometric & 2008 & $\begin{array}{l}\text { Direct inquiry and medical record review, excluding previous history of RF/ } \\
\text { RHD/invasive GAS, and last } 14 \text { days ST/SS, and fever on day of enrolment. }\end{array}$ \\
\hline Yemen $^{9}$ & $276 \mathrm{IU}$ & 404 & $5-15$ & ELISA & 2015 & $\begin{array}{l}\text { Direct inquiry and echocardiogram, excluding rheumatic heart disease } \\
\text { proven on echocardiogram, recent GAS pharyngitis and any evidence of } \\
\text { impetigo (including dry, crusted or pustule lesions). No information provided } \\
\text { on length of historical review. }\end{array}$ \\
\hline India (Mumbai) ${ }^{6}$ & $305 \mathrm{IU}$ & 40 & $5-15$ & $\begin{array}{l}\text { Microtitration haemolysin } \\
\text { inhibition }\end{array}$ & 2003 & $\begin{array}{l}\text { Source of data not specified; excluded use of antibiotic therapy for joint } \\
\text { pain, history of joint pain and features suggestive of sore throat in the last } \\
3 \text { months. No information provided on length of historical review for joint } \\
\text { pain. }\end{array}$ \\
\hline Australia (urban) ${ }^{10}$ & $320 \mathrm{IU}$ & 64 & $4-14$ & $\begin{array}{l}\text { Microtitration haemolysin } \\
\text { inhibition }\end{array}$ & 2005 & $\begin{array}{l}\text { Excluded history of sore throat, pyoderma lesion or other possible disease } \\
\text { caused by Streptococcus pyogenes in the preceding month ( } 4 \text { weeks), or } \\
\text { was immunocompromised due to illness or immunosuppressive therapy. } \\
\text { Source of data not specified. }\end{array}$ \\
\hline Korea $^{8}$ & $326 \mathrm{IU}$ & 266 & $7-12$ & ELISA & 2005 & $\begin{array}{l}\text { Throat cultures and blood samples obtained from } 266 \text { healthy children } \\
\text { (no signs or symptoms of streptococcal pharyngitis). Samples stratified } \\
\text { into three groups: contained S. pyogenes, contained non-group A beta- } \\
\text { haemolytic streptococci (BHS) and did not contain BHS. }\end{array}$ \\
\hline Ethiopia $^{15}$ & $360 \mathrm{IU}$ & 127 & $5-15$ & Latex agglutination & 2018 & $\begin{array}{l}\text { Medical records reviewed, excluded those with a recent history of tonsillitis } \\
\text { or impetigo. No information provided on length of historical review for } \\
\text { tonsillitis. }\end{array}$ \\
\hline Uganda (this study) & 389 IU & 181 & $5-14$ & Nephlometric & 2019 & $\begin{array}{l}\text { Direct inquiry and echocardiogram, excluded participants who had a } \\
\text { temperature of }>38.0^{\circ} \mathrm{C} \text { on the day of enrolment, history of acute rheumatic } \\
\text { fever, rheumatic heart disease evidence on echo or invasive GAS disease } \\
\text { and a history in the previous } 14 \text { days of sore throat or skin sores. }\end{array}$ \\
\hline Egypt $^{3}$ & $400 \mathrm{IU}$ & 660 & $5-10$ & Latex agglutination & 2011 & $\begin{array}{l}\text { Medical history and clinical examination; excluded recent history of } \\
\text { tonsillitis or sore throat. No information provided on length of historical } \\
\text { review for tonsillitis. }\end{array}$ \\
\hline
\end{tabular}

Table 3b ADB cut-off values for normal children ( $80 \%$ ULN)

\begin{tabular}{|c|c|c|c|c|c|c|}
\hline Country & ULN & $\mathrm{N}$ & Age range & Technique & Year published & Handling of recent streptococcal infections \\
\hline India (Mumbai) ${ }^{6}$ & $200 \mathrm{IU}$ & 40 & $5-15$ & $\begin{array}{l}\text { Microtitration haemolysin } \\
\text { inhibition }\end{array}$ & 2003 & See table $4.3 a$ \\
\hline Turkey $^{27}$ & $219.2 \mathrm{IU}$ & 121 & $5-15$ & Nephlometric & 2015 & $\begin{array}{l}\text { Direct inquiry, excluded previous history of streptococcal } \\
\text { infection, those exhibiting symptoms and signs of an } \\
\text { infection and those with upper respiratory tract and skin } \\
\text { infection within the previous } 3 \text { months. }\end{array}$ \\
\hline Australia (urban) ${ }^{10}$ & $300 \mathrm{IU}$ & 64 & $4-14$ & $\begin{array}{l}\text { Microtitration haemolysin } \\
\text { inhibition }\end{array}$ & 2005 & See table 4. 3a \\
\hline Korea $^{8}$ & $362 \mathrm{IU}$ & 266 & $7-12$ & Nephlometric & 2005 & See table 4. 3a \\
\hline Fiji $i^{11}$ & $499 \mathrm{IU}$ & 186 & $5-14$ & Enzyme inhibition assay & 2008 & See table 4. 3a \\
\hline Uganda (this study) & $568 \mathrm{IU}$ & 183 & $5-14$ & Enzyme inhibition assay & 2019 & See table 4. 3a \\
\hline USA $^{5}$ & $640 \mathrm{IU}$ & 1131 & $2-12$ & $\begin{array}{l}\text { Microtitration haemolysin } \\
\text { inhibition }\end{array}$ & 1997 & See table 4. 3a \\
\hline
\end{tabular}

ADB, antideoxyribonuclease B; ASO, antistreptolysin 0; GAS, group A streptococcal; ULN, upper limit of normal.

\section{CONCLUSION}

Our study provides the ULN normal values for streptococcal serology for children and adults in Uganda and demonstrates that using a single population-based cut-off, as compared with normal values by year of age, for normal versus abnormal titres is appropriate for children aged 5-14 years. Perhaps more importantly, these data also highlight that currently available tests for serological confirmation of recent GAS infection may not accurately reflect recent infection, in particular in populations with high background rates of GAS infection. There is a need for better tests that truly reflect recent infection rather than those that have occurred in the past months or even years, such as SpnA, which has shown early promise but is not commercially available. $^{26}$

\section{Author affiliations}

${ }^{1}$ Uganda Heart Institute Ltd, Kampala, Uganda

${ }^{2}$ Children's National Health System, Washington, District of Columbia, USA

${ }^{3}$ Telethon Kids Institute, University of Western Australia, Nedlands, Western Australia, Australia

${ }^{4}$ University of Western Australia, Crawley, Western Australia, Australia

${ }^{5}$ Case Western Reserve University School of Medicine, Cleveland, Ohio, United States

${ }^{6}$ University Hospitals Cleveland Medical Center, Cleveland, Ohio, United States

${ }^{7}$ London School of Hygiene and Tropical Medicine, London, UK

${ }^{8}$ University of Washington School of Medicine, Seattle, Washington, United States

${ }^{9}$ Dartmouth-Hitchcock School of Medicine, Dartmouth, New Hampshire, United States

${ }^{10}$ Cincinnati Children's Hospital Medical Center, Cincinnati, Ohio, USA

${ }^{11}$ University of Cincinnati School of Medicine, Cincinnati, Ohio, United States

Twitter Asha C Bowen @ashabowen 
Acknowledgements The authors would like to thank General Electric Healthcare for providing echocardiography equipment and all the study participants and staff members who participated in and assisted with this study.

Contributors $E O$ and $A B$ conceptualised and designed the study, collected data and drafted the initial manuscript and reviewed and revised the manuscript. MM, $J R$, ES and EN designed the data collection instruments, coordinated and supervised data collection, and reviewed and revised the manuscript. JA, GK, SK, IOO, LMO and JP collected data and reviewed and revised the manuscript. AB, NH, CTL, TP, CS, RS and $\mathrm{MZ}$ contributed to the conception and design of this work and critically reviewed the manuscript for important intellectual content. NdK and JC conceptualised and designed the study, carried out the initial analysis and reviewed and revised the manuscript. All authors gave final approval of this version for publication and agreed to be accountable for all aspects of the work in ensuring that questions related to the accuracy or integrity of any part of the work are appropriately investigated and resolved.

Funding This work was supported by American Heart Association Grant \#17SFRN33670607/Andrea Beaton/2017 and DELTAS Africa Initiative and the General Electric Foundation (donation of equpimtent for echocardiography).

Competing interests None declared.

Patient consent for publication Not required.

Ethics approval Institutional review board (IRB) approval was obtained from the Research and Ethics Committee at Makerere University School of Medicine, the Children's National Hospital IRB and the Uganda National Council for Science and Technology IRB

Provenance and peer review Not commissioned; externally peer reviewed.

Data availability statement De-identified individual participant data can be made availible through direct correspondance with the authors.

\section{ORCID iD}

Andrea Beaton http://orcid.org/0000-0002-4963-355X

\section{REFERENCES}

1 Carapetis JR, Steer AC, Mulholland EK, et al. The global burden of group A streptococcal diseases. Lancet Infect Dis 2005;5:685-94.

2 Gewitz MH, Baltimore RS, Tani LY, et al. Revision of the Jones criteria for the diagnosis of acute rheumatic fever in the era of Doppler echocardiography: a scientific statement from the American heart association. Circulation 2015;131:1806-18

3 Kotby AA, Habeeb NM, Ezz El Elarab S. Antistreptolysin 0 titer in health and disease: levels and significance. Pediatr Rep 2012;4:e8.

4 Wannamaker LW, Ayoub EM. Antibody titers in acute rheumatic fever. Circulation 1960:21:598-614

5 Kaplan EL, Rothermel CD, Johnson DR. Antistreptolysin 0 and anti-deoxyribonuclease B titers: normal values for children ages 2 to 12 in the United States. Pediatrics 1998; 101:86-8.

6 Karmarkar MG, Venugopal V, Joshi L, et al. Evaluation \& revaluation of upper limits of normal values of anti-streptolysin 0 \& anti-deoxyribonuclease B in Mumbai. Indian J Med Res 2004:119:26-8.

7 Sethi S, Kaushik K, Mohandas K, et al. Anti-Streptolysin 0 titers in normal healthy children of 5-15 years. Indian Pediatr 2003:40:1068-71.
8 Kim S, Lee NY. Asymptomatic infection by Streptococcus pyogenes in schoolchildren and diagnostic usefulness of antideoxyribonuclease B. J Korean Med SCi 2005;20:938-40.

9 Khaled A, Hassan A, Anti Streptolysin O. Normal Values for Healthy Children Aged from 5 to 15 Years Old in Sana'a City-Yemen. Annals of Clinical and Laboratory Research 2015:3:1-5.

10 Danchin MH, Carlin JB, Devenish W, et al. New normal ranges of antistreptolysin 0 and antideoxyribonuclease B titres for Australian children.J Paediatr Child Health 2005:41:583-6.

11 Steer AC, Vidmar S, Ritika R, et al. Normal ranges of streptococcal antibody titers are similar whether streptococci are endemic to the setting or not. Clin Vaccine Immunol 2009;16:172-5.

12 Anonymous. Human development report 2017. New York, NY: United Nations Development Programme, 2017.

13 Reményi B, Wilson N, Steer A, et al. World Heart Federation criteria for echocardiographic diagnosis of rheumatic heart disease--an evidence-based guideline. Nat Rev Cardiol 2012:9:297-309.

14 Wright E, Royston P. Age-specific reference intervals ("normal ranges"), 1997.

15 Asfaw T, Shenkute D, Tilahun M. Antistreptolysin 0 titers: normal values for children ages 5 to 15 at Debre Berhan referral Hospital, Ethiopia. Journal of Family Medicine and Health Care 2018:4:1-4.

16 Parks T, Smeesters PR, Curtis N, et al. ASO titer or not? when to use streptococcal serology: a guide for clinicians. Eur J Clin Microbiol Infect Dis 2015;34:845-9.

17 Jack S, Moreland NJ, Meagher J, et al. Streptococcal serology in acute rheumatic fever patients: findings from 2 high-income, high-burden settings. Pediatr Infect Dis J 2019:38:e1-6.

18 DeWyer A, Scheel A, Webel AR, et al. Prevalence of group A $\beta$-hemolytic streptococcal throat carriage and prospective pilot surveillance of streptococcal sore throat in Ugandan school children. Int J Infect Dis 2020;93:245-51.

19 Beaton A, Lu JC, Aliku T, et al. The utility of handheld echocardiography for early rheumatic heart disease diagnosis: a field study. Eur Heart I Cardiovasc Imaging 2015; 16:475-82

20 Beaton A, Okello E, Lwabi P, et al. Echocardiography screening for rheumatic heart disease in Ugandan schoolchildren. Circulation 2012;125:3127-32.

21 Ploutz M, Lu JC, Scheel J, et al. Handheld echocardiographic screening for rheumatic heart disease by non-experts. Heart 2016;102:35-9.

22 Okello E, Wanzhu Z, Musoke C, et al. Cardiovascular complications in newly diagnosed rheumatic heart disease patients at Mulago Hospital, Uganda. Cardiovasc $\lrcorner$ Afr 2013:24:76-9.

23 Okello E, Longenecker CT, Beaton A, et al. Rheumatic heart disease in Uganda: predictors of morbidity and mortality one year after presentation. BMC CardiovasC Disord 2017;17:20

24 Johnson DR, Kurlan R, Leckman J, et al. The human immune response to streptococcal extracellular antigens: clinical, diagnostic, and potential pathogenetic implications. Clin Infect Dis 2010;50:481-90.

25 Hysmith ND, Kaplan EL, Cleary PP, et al. Prospective longitudinal analysis of immune responses in pediatric subjects after pharyngeal acquisition of group A streptococci. J Pediatric Infect Dis Soc 2017:6:187-96.

26 Hanson-Manful P, Whitcombe AL, Young PG, et al. The novel group A Streptococcus antigen SpnA combined with bead-based immunoassay technology improves streptococcal serology for the diagnosis of acute rheumatic fever. J Infect 2018:76:361-8.

27 Delice S, Adaleti R, Cevan S, et al. Detection of upper limit of normal values of anti-DNase $B$ antibody in children's age groups who were admitted to hospital with noninfectious reasons. North Clin Istanb 2015:2:136-41. 